\title{
Estimates of maternal risks of pregnancy for women with hereditary haemorrhagic telangiectasia (HHT, Osler-Weber-Rendu syndrome): suggested approach for obstetric services
}

\section{${ }^{1}{ }^{2} \mathbf{C}$ L Shovlin, ${ }^{3} \mathbf{V}$ Sodhi, ${ }^{4} \mathbf{A}$ McCarthy, ${ }^{5} \mathbf{P}$ Lasjaunias, ${ }^{6} \mathbf{J}$ E Jackson, ${ }^{7} \mathbf{M} \mathbf{N}$ Sheppard}

${ }^{1}$ NHLI Cardiovascular Sciences, Imperial College London; ${ }^{2}$ Respiratory Medicine and ${ }^{6}$ Department of Imaging, Hammersmith Hospital, ${ }^{3}$ Anaesthetics and ${ }^{4}$ Obstetrics, Queen Charlotte's Hospital, London W12 ONN, ${ }^{7}$ Histopathogy, Royal Brompton Hospital, London. ${ }^{5}$ Neuroradiologie, Bicêtre Hospital, 94275 Kremlin Bicetre, France

Address for correspondence and reprint requests:

Dr Claire Shovlin PhD MA FRCP

BHF Cardiovascular Medicine Unit

National Heart and Lung Institute

Imperial College Faculty of Medicine

Hammersmith Hospital

Du Cane Road

London

W12 0NN

UK.

PHONE +44-208-383-4831

EMAIL: $\quad$ c.shovlin@imperial.ac.uk

\section{Running title: HHT and pregnancy}

Word counts: Abstract 252; Text and tables 3,165 


\begin{abstract}
Objectives: Hereditary haemorrhagic telangiectasia (HHT) affects 1 in 5-8,000 individuals. Pregnancy outcomes are rarely reported. The major reason is that most women do not have their HHT diagnosed prior to pregnancy. Utilising a large wellcharacterised series, we studied all pregnancies known to have occurred in HHT-affected women, whether or not their diagnosis was known at the time of pregnancy. Our aim was to estimate rates and types of major complications of HHT in pregnancy, to guide management decisions.
\end{abstract}

Design: Cohort study, with prospective, retrospective and familial components.

Setting/ Population: Tertiary referral centre population

Methods: All 262 pregnancies in the 111 women with HHT and pulmonary arteriovenous malformations (PAVMs) reviewed between 1999 and 2005 were studied. $82(74 \%)$ did not have a diagnosis of HHT/PAVM at the time of pregnancy. 222 pregnancies in their $86 \mathrm{HHT}$-affected relatives were also studied.

Main outcome measures: Maternal death, haemoptysis, haemothorax, stroke.

Results: Thirteen women experienced life-threatening events during pregnancy: $1.02 \%$ (95\% confidence intervals $0.13,1.92 \%$ ) of pregnancies resulted in a major PAVM bleed; $1.24 \%(0.25,2.23 \%)$ in stroke (not all were HHT-related); and $1.00 \%(0.13,1.92 \%)$ in maternal death. All deaths occurred in women previously considered well. In women experiencing a life-threatening event, prior awareness of HHT or PAVM diagnosis was 
associated with improved survival in women experiencing a life-threatening event $(p=0.041$, Fisher's exact test).

Conclusions: Most HHT pregnancies proceed normally. Rare major complications, and improved survival outcome following prior recognition, means that pregnancy in a woman with HHT should be considered high risk. Recommendations for pregnancy management are provided.

Key words: nose bleeds, arteriovenous malformations, haemorrhage, pulmonary, cerebral, myocardial infarction

\section{Introduction}

Hereditary haemorrhagic telangiectasia (HHT, Osler-Weber-Rendu syndrome), is a relatively common genetic condition affecting 1 in 5-8,000 Europeans ${ }^{1,2}$. Most affected individuals are unaware of their diagnosis ${ }^{3,4}$. This is particularly true of younger individuals since the main clinical manifestations of recurrent nosebleeds, characteristic mucocutaneous telangiectasia and anaemia are either considered normal (nosebleeds), or become prominent later in life ${ }^{5,6}$. HHT-affected individuals also commonly have silent arteriovenous malformations (AVMs). Screening programmes in asymptomatic individuals indicate that these occur at significant frequencies. Pulmonary AVMs are now estimated to affect at least $48 \%$ of HHT patients ${ }^{7}$; cerebral AVMs up to $10 \%^{8}$; 
hepatic AVMs approximately $30 \%{ }^{9}$, with spinal AVM frequencies estimated at between $0.3-1 \%$.

In normal pregnancy, complex physiological vasodilatory responses are associated with the increase in cardiac output that approaches $50 \%$ by the end of the second trimester ${ }^{10}$. Cardiac chamber ${ }^{10}$ and aortic ${ }^{11}$ dimensions increase in normal pregnancies. Effects on the HHT vascular bed would be predicted.

Two series of pregnancy outcomes in HHT have been reported. Goodman et al performed a retrospective study of $40 \mathrm{HHT}$ patients (recruited from an ENT clinic) compared to 80 controls matched for age, ethnicity, religion and health care ${ }^{12}$. The rates of miscarriage per pregnancy (14.4\% versus 9.9\%, HHT figures given first), and abnormal outcome per individual (50\% versus $42.3 \%$ ) did not differ statistically between the two groups. In a retrospective series of 161 pregnancies in HHT-affected women and family members recruited from a clinic with a PAVM bias, no excess rate of miscarriage was reported ${ }^{13}$. There was a significant increase in maternal complications in women with PAVMs: overall, 2 maternal deaths (PAVM haemorrhage), 6 cases of PAVM shunt deterioration and three maternal strokes were reported ${ }^{13}$.

In addition to these series, there have been case reports of HHT complications during pregnancy: Pulmonary AVM-related haemorrhage ${ }^{14-20}$, and growth of pulmonary AVMs 13, 15, 16, 21, 22 have been reported during pregnancy. HHT-related cerebral AVMs have presented or haemorrhaged in the third trimester ${ }^{23-25}$. It is recognised however, that in pregnancy and in general, cerebral AVMs are associated with lower rates of haemorrhage ${ }^{25,} 26$ than cerebral aneurysms, which affect $3 \%$ of the general population ${ }^{27}$ and may be familial $^{28,29}$. 
Patient group websites (www.hht.org; telangiectasia.co.uk) mean many women with HHT are aware of HHT-specific pregnancy risks. In contrast, most HHT pregnancies will be managed by obstetric teams with little personal experience of HHT, since HHT will affect only two in 10,000 women. How should such teams place the recognised pregnancy-related risks in context for a healthy woman approaching pregnancy with a known diagnosis of HHT, and how should pregnancy management differ?

In order to facilitate more informed management decisions, pregnancy outcomes were studied in our well-characterised 1999-2006 Hammersmith HHT/PAVM cohort. The statsistical power of studies on rare diseases such as HHT and PAVMs is difficult due to the relatively small number of affected patients (fewer than 450 reported in world literature prior to 1998; 27 referred to British Thoracic Society BOLD project between 1999-2007). Under these circumstances, utilisation of retrospective arms and novel statistical methods may be essential to ascertain an evidence base for clinical practice and research priorities, as recently reported by us for stroke, brain abscess and thrombotic complications ${ }^{3,36}$.

Here we report an approach that allowed two major questions to be addressed: First, whether estimates of absolute risks of pregnancy could be established; and second, whether recognition of at-risk status might improve outcome in the event of a life threatening HHT complication during pregnancy. The findings were utilised to develop recommendations for pregnancy management. 


\section{Methods}

\section{Study setting and participants}

Analysis of patient records was approved by Hammersmith, Queen Charlotte's, Chelsea, and Acton Hospital Research Ethics Committee (LREC 2000/5764).

The study populations comprised the 205 consecutive men and women with HHT and pulmonary AVMs (from 181 different HHT families) who were reviewed in the Hammersmith Hospital PAVM clinical service between May 1999 and May 2005, followed up until May 2006. A diagnosis of HHT was assigned according to the presence of at least three established international criteria, namely recurrent nosebleeds, mucocutaneous telangiectasia (Figure 1), visceral involvement, and family history ${ }^{30}$ : All individuals were screened for the presence of pulmonary AVMs using imaging (thoracic CT scan unless the chest X-ray was diagnostic), and all individuals with pulmonary AVMs large enough for treatment underwent coil embolization as described previously 31. In keeping with current recommended clinical practice in Europe, screening of asymptomatic individuals for the presence of cerebral ${ }^{32}$ or hepatic ${ }^{9}$ vascular malformations was not performed.

\section{Pregnancy groups}

While a prospective study was initiated, only 18 women had pregnancies following review by us. Most pregnancies occurred in women prior to review. In the majority of these women, pregnancies occurred prior to PAVM diagnosis which in turn, was usually prior to the diagnosis of $\mathrm{HHT}^{3}$. In order to record life-threatening events that were less likely to have occurred in women who survived their pregnancies, we also studied the pregnancies of the women's first degree relatives who were affected by HHT as denoted by recurrent nosebleeds, telangiectasia or other HHT complications. 222 pregnancies 
occurred in these 86 HHT-affected women. Again, the majority of pregnancies occurred prior to HHT/PAVM recognition. Table 1 summarises the features of these three groups.

Table 1

\begin{tabular}{|l|l|l|l|}
\hline Group & Women & Pregnancies & $\begin{array}{l}\text { HHT or PAVM diagnosis at time of } \\
\text { pregnancy }(\%, \text { proportion })\end{array}$ \\
\hline Prospective & 16 & 23 & $100 \%(23 / 23)$ \\
\hline Retrospective & 97 & 239 & $8.3 \%(20 / 239)$ \\
\hline Relatives & 86 & 222 & $5.4 \%(12 / 222)$ \\
\hline
\end{tabular}

\section{i) Prospective group:}

Women in the prospective group received intervention and pre-pregnancy advice that may have influenced pregnancy outcomes. Fifteen underwent PAVM embolisation treatment prior to pregnancy. In addition, pregnant women, their obstetric team, and local doctors were provided with advice developed following our earlier manuscript ${ }^{13}$, and subsequent discussions. This information advised of the small risk of haemoptysis to be considered a medical emergency if it occurred in pregnancy, and the potential presence of cerebral and spinal AVMs. We suggested that women with HHT were managed as though they had cerebral AVMs, noting that theoretical concerns, and evidence of rupture of cerebral AVMs and aneurysms during vaginal and Caesarean deliver, influence general obstetric anaesthetic practice ${ }^{33,34}$. At our institution, a prolonged second stage of labour was avoided to minimise Valsalva manoeuvres, and if general anaesthesia was required, modified induction regimes with opiates were used to attenuate the hypertensive response to laryngoscopy. Although the anaesthetic technique 
was protective for the mother, placental transfer of opiate is well recognised and thus this was not ideal for the baby. At our institution, we withheld regional analgesia/anaesthesia unless spinal AVMs had been excluded..

Retrospective and relatives groups:

Occurrence and outcome of all pregnancies were documented during a detailed personal history (retrospective group) or family history (relatives group). None of the women in these groups had received detailed information of possible pregnancy risks. Where haemoptysis, stroke or maternal death had occurred, with consent from the proband, further information was obtained from the relevant medical, obstetric, radiological or pathology services. Histopathology samples and original imaging were reviewed.

\section{Statistics}

Basic statistics and univariate analyses were performed using Prism 4 (Graph Pad Software Inc, San Diego): Continuous variables were compared by two-sided Mann Whitney test, binary variables using Fisher's exact test. Fisher's exact test was used to test the null hypothesis that prior recognition of HHT/PAVM status did not affect outcome in the event of pregnancy-related haemorrhagic complications. Significance was assessed at false discovery rate $(\mathrm{FDR})=0.05$ level $^{35}$.

\section{Results}

Complications occurred in first $(n=6)$, second $(n=7)$ and third or greater $(n=5)$ pregnancies, as summarised in Table 2. 
Table 2 Maternal outcomes of 484 HHT pregnancies:

\begin{tabular}{|c|c|c|c|c|}
\hline & Prospective & Retrospective & Relatives & Combined \\
\hline Pregnancies N & 23 & 239 & 222 & 484 \\
\hline Women $\mathrm{N}$ & 16 & 97 & 86 & 199 \\
\hline Maternal deaths N (\% pregnancies; $95 \% \mathrm{CI})$ & 0 & 0 & $5(2.3 ; 0.29,4.2 \%)$ & $5(1.00 ; 0.13,1.92 \%)$ \\
\hline PAVM haemorrhage N (\% pregnancies; 95\%CI) & $2(4.3 ;-4.7,13.5 \%)$ & $2(0.84 ; 0.033,2.0 \%)$ & $2(0.9 ;-0.35,2.2 \%)$ & $6(1.36 ; 0.17,2.54 \%)$ \\
\hline Strokes N (\% pregnancies, $95 \% \mathrm{CI})$ & 0 & $3(1.3 ;-0.17,2.7 \%)$ & $3(1.4 ;-0.18,2.9 \%) \dagger$ & $6(1.24 ; 0.25,2.23)$ \\
\hline Myocardial infarction $\S \mathrm{N}(\%$ all pregnancies, & 0 & 0 & $1(0.45 ;-0.44,1.4)$ & $1(0.21 ;-0.20,0.61)$ \\
\hline Spinal haemorrhage & 0 & 0 & 0 & 0 \\
\hline
\end{tabular}




\section{Pulmonary AVM haemorrhage}

There were six PAVM haemorrhages in the prospective and retrospective groups, as detailed in Figure 2A, B. Four of these women had had previous PAVM embolization at four different institutions. Two women were treated by embolization of pulmonary or systemic arterial supply to the PAVM, and two women underwent emergency thoracotomy for surgical resection or cauterisation of PAVMs. Major haemoptysis was also reported in six relatives, leading to the two previously reported cases of maternal death ${ }^{13}$, and two further fatalities in the first post partum year.

Overall, the rate of life-threatening bleeds from pulmonary AVMs was $1.36 \%(0.17$, $2.54 \%)$ during pregnancy/delivery: events occurred in the second trimester $(n=1)$, start of the third trimester $(n=6)$, immediately post Cesarian section $(n=1)$. The rate of lifethreatening bleeds from pulmonary AVMs in the post partum year was $0.63 \%(95 \% \mathrm{CI}$ $0.08,1.3 \%)$. These figures contrast with the full series of women ${ }^{3}$ in which major haemoptysis affected only two outside of pregnancy, and there were no haemothoraces.

\section{Strokes in pregnancy}

There were three significant strokes during pregnancy in the patient group. Two occurred in the first trimester, were of ischaemic aetiology and were attributed to paradoxical emboli through pulmonary AVMs ${ }^{3}$ that were subsequently embolised. A third was a subarachnoid haemorrhage as previously reported ${ }^{13}$. All women made good recoveries and the pregnancies subsequently proceeded normally.

In relatives, three third trimester strokes were also reported. Two were fatal, one due to rupture of an internal carotid artery aneurysm at 7 months gestation (Figure 2C), and a 
second due to undefined pathology during childbirth leading to maternal death. A third resulted in a hemiplegic stroke in the $7^{\text {th }}$ month of pregnancy. An abnormal vessel was surgically resected after a Cesarean section under general anesthesia, and the woman went on to have a further uncomplicated pregnancy.

\section{Maternal death}

No maternal deaths occurred in the patient group comprising a small prospective group of 23 pregnancies, and large retrospective group of 239 pregnancies for which survival was a prerequisite. In the relatives' group which did not have this 'survival to review' bias, there were five deaths. One was due to an acute transmural myocardial infarction in a 16 year old at 32 weeks gestation (Figure 2D), two deaths were due to haemoptysis ${ }^{13}$, and two were due to haemorrhagic strokes. The overall maternal death rate was $1.00 \%$ of pregnancies $(95 \%$ confidence limits $0.13,1.92$, Table 1$) ; 2.51 \%(0.32,4.71)$ of women. All deaths in our series occurred in women previously considered well and not under medical review for HHT.

In the event of a life-threatening event, there was a statistically significant improvement in survival in women in whom the diagnosis of HHT or PAVMs had been made previously: Of the 17 women with haemoptysis/haemothorax, stroke or myocardial infarction, five had a known diagnosis of PAVM (for haemoptysis) or HHT at the time, and all five survived with their infants. Of the twelve other women, whose haemorrhagic complications during pregnancy occurred prior to the diagnosis of HHT or PAVMs, seven died and five survived ( $p=0.041$ Fisher's exact test). 


\section{Discussion}

Between 1985 and 2005, all cause UK maternal mortality rates ranged from 0.010$0.014 \%{ }^{38}$. Our data demonstrate that in HHT, while the vast majority of pregnancies proceed uneventfully, the mortality rate is significantly increased, due to PAVM haemorrhage, strokes and myocardial infarction. Life-threatening events occurred in women who had few manifestations of HHT prior to pregnancy, but prior awareness of HHT/PAVM diagnosis was associated with a statistically improved survival outcome for mother (and infant) in the event of a major complication.

The strengths of this study include large numbers examined for a rare condition: This is particularly important since it is not possible to ascertain HHT-related death rates from recent Confidential Enquiries into Maternal and Child Health (CEMACH) reports in which events would be classified as 'other indirect' causes of death ${ }^{38}$. Furthermore, most individuals with HHT are unaware of their diagnosis, and maternal death in pregnancy may be a precipitation for family review and referral. Previous small series are therefore likely to have over-represented maternal risks due to ascertainment bias, as in our previous pregnancy series ${ }^{13}$. However the overall types of complications are similar to those previously reported here, namely PAVM-related haemorrhage, and stroke.

Potential biases present included referral bias (pregnancy complications in a relative biasing the referring physician towards referral), and the pulmonary AVM focus of our clinical practice. In addition, in order to reduce bias due to intervention, or survival to review, it was essential to capture data in relatives in whom the diagnosis of HHT was made from a reported history or transmission to children. This method is likely to have led to a failure to capture all affected individuals. For these reasons, we suspect that the 
overall risks of pregnancy may be revised downwards. Importantly however, we are aware of three other relatively recent UK PAVM-haemorrhage deaths in pregnancy that were not captured by our series.).

Many complications in the HHT pregnancies occurred in the second and third trimesters, at the time of reduced peripheral resistance and increased cardiac output, and reduced systemic vascular resistance ${ }^{10}$. Similar timings are observed in haemorrhages from nonHHT cerebral AVMs ${ }^{27}$. We therefore anticipate that the haemorrhages in our population occurred as a result of general pregnancy responses leading to aberrant haemodynamic and other stresses in an abnormal vascular bed, as opposed to an HHT-specific response to pregnancy.

The reported survival advantage of prior recognition of HHT/PAVM status is encouraging. We presume this operates by heightened patient and physician awareness of potential complications and novel symptoms. While emergency intervention is likely to need to be managed on a case-by-case basis, prior recognition (and pre-planning of management in the event of a complication) may be sufficient for local obstetric services to optimise outcomes in the event of a rare complication, including emergency delivery where maternal survival is unlikely.

The data allow some preliminary guidance for clinical management, which is summarised in Table 3. In almost all cases in this series, and those known subsequently to us, there was sufficient time after the onset of symptoms to allow for hospital admission and intervention. Thus all pregnancies with HHT should be considered high risk, and women should be advised about the small but serious risks, though re-assured that these appear less threatening where medical and obstetric services are aware of the complications. 
Advice to all maternity health care providers needs to emphasise the need for immediate referral should haemoptysis or dyspnoea occur.

In general for HHT-affected adults, screening and treatment of pulmonary AVMs is recommended to reduce later complications such as paradoxical embolic stroke and haemorrhage. The management of asymptomatic women found to have pulmonary AVMs during pregnancy is not as clear-cut as for non-pregnant individuals. During pregnancy, our data have shown that the risk of pulmonary AVM-associated complications is low; furthermore, there is no reported evidence that embolization of pulmonary AVMs during pregnancy in women who have not experienced a complication reduces the risk of haemorrhage or ischaemic stroke in the second and third trimester. The risks associated with PAVM embolization are small but the procedure does involve ionizing radiation and, as with any intervention, there is the potential for complications. For these reasons, we do not feel that PAVM screening and treatment of asymptomatic individuals during pregnancy is justified.

Screening for cerebral AVMs could simplify obstetric anaesthetic management for the $90 \%$ of individuals in whom no cerebral AVM or aneurysm would be detected, but there are several concerns. First, such scans may lead to false reassurance since small cerebral AVMs are not detectable by MRI, and pregnancy itself precipitates the growth of many AVMs such that pre or early-pregnancy assessment of AVM presence or size may not be relevant to the situation in late pregnancy or delivery. Secondly, up to one in ten women will be found to have an asymptomatic cerebral AVM. European risk-benefit analyses of treatment of asymptomatic cerebral AVMs in the general HHT population are not interpreted in favour of treatment ${ }^{33}$. The published literature, and our current data, do not suggest that pregnancy substantially alters these considerations. Thus up to $10 \%$ of 
women would be faced with the identification of cerebral AVMs for which treatment would not be recommended at the current time. For any individual, it is difficult to judge how well they would cope with this knowledge ${ }^{40}$. Whether the obstetric anaesthetic considerations justify subjecting women in pregnancy to these concerns needs further informed discussion.

Spinal AVMs in non-HHT individuals have been punctured by epidural needles resulting in paraparesis ${ }^{41}$. This has led some obstetric anaesthetic practices, including our own, to avoid regional anaesthesia, in turn, increasing the likelihood of a general anaesthetic. Were spinal AVMs to be excluded, epidurals could be employed with greater reassurance. Furthermore, in the unlikely event that spinal AVMs were detected, pregnancy management could be optimised to minimise risks of obstructed venous drainage, and since few bleeds have been reported, the associated anxiety would be substantially lower than for detection of a cerebral AVM.

Table 3: Summary of recommendations for management of HHT pregnancies

General

\begin{tabular}{|l|l|}
\hline & Consider all HHT pregnancies 'high-risk'; \\
\hline & $\begin{array}{l}\text { Advise that there are rare pregnancy-associated risks, but outcome is better if mother } \\
\text { and obstetric services are pre-warned. }\end{array}$ \\
\hline $\begin{array}{l}\text { Highlight any haemoptysis/severe dyspnoea as red flag symptoms to prompt } \\
\text { immediate hospital admission }\end{array}$ \\
\hline
\end{tabular}

PAVMS

\begin{tabular}{|l|l|}
\hline & Pre-pregnancy screening $\dagger$ and treatment of PAVMs \\
\hline & No PAVM screening and treatment of asymptomatic individuals during pregnancy \\
\hline
\end{tabular}

Cerebral haemorrhage

\begin{tabular}{|l|l|}
\hline & $\begin{array}{l}\text { For women with HHT with FH of cerebral haemorrhage or cerebral symptoms, } \\
\text { cerebral MRI }\end{array}$ \\
\hline & For the majority of women with HHT, no cerebral MRI screen \\
\hline
\end{tabular}


Delivery

\begin{tabular}{|l|l|}
\hline & Provide antibiotic prophylaxis during delivery $\$$ \\
\hline & $\begin{array}{l}\text { Avoid prolonged second stage of labour in women in whom cerebral AVMs have not } \\
\text { been excluded }\end{array}$ \\
\hline & $\begin{array}{l}\text { In the rare situations when general anaesthesia is required, use a modified induction } \\
\text { regime utilising opiates }\end{array}$ \\
\hline
\end{tabular}

Legend: $†$ While discussion continues regarding the optimal mode of screening of individuals with HHT ${ }^{39}$, a diagnosis can be made efficiently and quickly using a thoracic CT scan ${ }^{3}$. $\$$ In keeping with general advice regarding dental and surgical procedures for individuals with PAVMs ${ }^{7}$ and/or HHT $^{3}$

In summary, our data indicate that the majority of HHT pregnancies proceed uneventfully, but that there are significant maternal risks. Survival outcome may be improved by prior recognition of HHT/PAVM status. Recommendations for pregnancy management in individuals with HHT are discussed and proposed.

\section{Acknowledgements}

Dr Shovlin thanks the British HHT families whose donations supported this study, Vibha Barochia for Figure 4A/B, and Georgina Rudd for clinical secretarial help. She particularly thanks the many individuals who recounted difficult obstetric histories and/or arranged for radiological or histopathological material to be forwarded.

\section{Disclosure of interest statement.}

None declared. 


\section{Contribution to authorship:}

CLS designed the study, reviewed the full patient cohort and records, generated the database, performed Prism 4 statistical calculations and wrote the manuscript. VS, AM and JEJ reviewed patients and interpreted data. PL interpreted cerebral scans. MS interpreted histopathology samples. Management strategies were devised by CLS, VS, AM, PL and JEJ. All authors contributed to and reviewed the final manuscript.

\section{Details of ethics approvals}

All studies were ethically approved by the Hammersmith, Queen Charlotte's, Chelsea, and Acton Hospital Research Ethics Committee (LREC 2000/5764) and registered on www.clinicaltrials.gov (NCT00230685).

\section{Funding}

This study was funded by donations from British HHT families. We are also grateful for support from the NIHR Biomedical Research Centre Funding Scheme. The funding sources played no part in the design, conduct or reporting of the study, nor in the decision to submit the paper for publication.

\section{References}

1. Bideau A, Plauchu H, Brunet G, Robert J-M. Etude épidémiologique de la maladie de Rendu-Osler disease en France. Population 1989;1:9-28.

2. Kjeldsen AD, Vase P, Green A. Hereditary haemorrhagic telangiectasia: a population-based study of prevalence and mortality in Danish patients. J Intern Med 1999;245:31-39.

3. Shovlin CL, Jackson JE, Jenkins IH, Bamford K, Benjamin A, Ramadan H, Kulinskaya E. Primary determinants of ischaemic stroke and cerebral abscess are 
unrelated to severity of pulmonary arteriovenous malformations in HHT. Thorax doi:10.1136/thx.2007.087452, publication date 02 Nov 07

4. Shovlin CL, Simonds AK, Hughes JMB. Pulmonary disease and cor pulmonale. In: Oakley C, Warnes CA, editors. Heart disease in pregnancy. 2nd ed. Oxford: Blackwell; 2007. 151-172.

5. Plauchu H, de Chadarévian J-P, Bideau A, Robert J-M. Age-related clinical profile of hereditary hemorrhagic telangiectasia in an epidemiologically recruited population. Am J Med Genet 1989;32:291-297.

6. Begbie ME, Wallace GMF, Shovlin CL. Hereditary haemorrhagic telangiectasia (Osler-Weber-Rendu syndrome): A view from the 21st century. Postgrad Med J 2003;79:18-24.

7. Cottin V, Plauchu H, Bayle J-Y, Barthelet M, Revel D, Cordier JF. Pulmonary arteriovenous malformations in patients with hereditary hemorrhagic telangiectasia. Am J Respir Crit Care Med 2004;169(9):994-1000.

8. Willemse RB, Mager JJ, Westermann CJJ, Overtoom TT, Mauser H, Wolbers JG. Bleeding risk of cerebrovascular malformations in hereditary haemorrhagic telangiectasia. J Neurosurgery 2000;92:779-784.

9. Buscarini E, Plauchu H, Garcia Tsao G, White RI, Sabba C, Miller F, Saurin JC, Pelage JP, Lesca G, Marion MJ, Perna A, Faughnan ME. Liver involvement in hereditary hemorrhagic telangiectasia: consensus recommendations. Liver International 2006;26:1040-1046.

10. Silverside CK, Colman JM. Physiological changes during pregnancy. In: Oakley C, Warnes CA, editors. Heart disease in pregnancy. 2nd ed. Oxford: Blackwell; 2007. p. 6-17.

11. Hart MV, Morton MJ, Hosenpud JD, Metcalfe J. Aortic function during normal human pregnancy. Am J Obstet Gynecol 1986;154:887-891. 
12. Goodman RM, Gresham GE, Roberts PL. Outcome of pregnancy in patients with hereditary hemorrhagic telangiectasia. Fertility and Sterility 1967;18:272-277.

13. Shovlin CL, Winstock AR, Peters AM, Jackson JE, Hughes JMB. Medical complications of pregnancy in hereditary haemorrhagic telangiectasia. Quart J Med $1995 ; 88: 879-887$.

14. Moore BP. Pulmonary arterio-venous fistula. Thorax 1969;24:381.

15. Swinburne AJ, Fedulla AJ, Gangemi R, Mijangos JA. Hereditary telangiectasia and multiple pulmonary arteriovenous fistulas. Clinical deterioration during pregnancy. Chest 1986;89(3):459-460.

16. Gammon RB, Miska AK, Keller FS. Osler-Weber-Rendu disease and pulmonary arteriovenous fistulas. Deterioration and embolotherapy during pregnancy. Chest $1990 ; 98: 1522-1524$.

17. Laroche CM, Wells F, Schneerson J. Massive hemothorax due to enlarging arteriovenous fistula in pregnancy. Chest 1992;101:1452-1454.

18. Bevalaqua FA, Ordorica SA, Lefleur R, Young B. Osler Weber Rendu disease. Diagnosis and management of spontaneous hemothorax during pregnancy. New York State J Med 1992;92(12):551-552.

19. Chanatry BJ. Acute haemothorax owing to pulmonary arteriovenous malformation in pregnancy. Anesth Analg 1992;74:613.

20. Ference BA, Shannon TM, White RI, Zawin M, Burdge CM. Life threatening pulmonary hemorrhage with pulmonary arteriovenous malformations and hereditary hemorrhagic telangiectasia. Chest 1994;106:1387-1392.

21. Hoffman R, Rabens R. Evolving pulmonary nodules: Multiple pulmonary arteriovenous fistulas. Am J Radiol 1974;120(4):861-864.

22. Eplin MS, Varner MW. Progression of pulmonary arteriovenous malformation during pregnancy: case report and review of the literature. Obstet Gynecol Surv 1997;52:248-53. 
23. Neau JP, Roualdes G, Bataille B, Muckensturm B, Rivasseau T, Gil R, Lefevre JP, Salles M. Recurrent intracranial haematomas disclosing Rendu-Osler disease in a pregnant woman. Neurochirugie 1988;34:64-67.

24. Lesser BA, Wendt D, Miks VM, Norum RA. Identical twins with hereditary hemorrhagic telangiectasia concordant for cerebrovascular arteriovenous malformations. Am J Med 1986;81(5):931-934.

25. Velut S, Vinikoff L, Destrieux C, Kakou M. Cerebro-meningeal hemorrhage secondary to ruptured vascular malformation during pregnancy and post-partum. Neurochirurgie 2000;46:95-104.

26. Horton JC, Chambers WA, Lyons SL, Adams RD, Kjellberg RN. Pregnancy and the risk of hemorrhage from cerebral arteriovenous malformations. Neurosurgery. 1990;27:867-71.

27. Kirkpatrick PJ, McConnell RS. Screening for familial intracranial aneurysms. No justification for screening exists. Brit Med Journal 1999;319:1512-1513.

28. Chambers WR, Harper BF, Simpson JR. Familial incidence of congenital aneurysms of cerebral arteries: report of cases of ruptured aneurysm in father and son. JAMA $1954 ; 155: 358-359$

29. Schievink WI, Mokri B, Michels VV, Piepgras DG. Familial association of intracranial aneurysms and cervical artery dissections. Stroke 1991;22:1426-1430.

30. Shovlin CL, Guttmacher AE, Buscarini E, Faughan M, Hyland R, Westermann CJJ, Kjeldsen AD, Plauchu H. Diagnostic criteria for hereditary hemorrhagic telangiectasia (Rendu-Osler-Weber syndrome). Am J Med Genet 2000;91:66-67.

31. Gupta P, Mordin C, Curtis J, Hughes JMB, Shovlin CL, Jackson JE. Pulmonary arteriovenous malformations: Effect of embolization on right-to-left shunt, hypoxaemia and exercise tolerance in 66 patients. Am J Roent 2002;179:347-55.

32. Lasjaunias P. Cerebro medullary arteriovenous locations in children and adults with HHT. Haematology Meeting Reports 2007;1:43. 
33. Sharma SK, Herrera ER, Sidawi JE, al e. The pregnant patient with an intracranial arteriovenous malformation: cesarean or vaginal delivery using regional or general anaesthesia? Reg Anesth 1995;20:455-458.

34. English L, Mulvey D. Ruptured arteriovenous malformation and subarachnoid hemorrhage during emergent cesarean delivery: a case report. AANA J 2004;72:4236.

35. Benjamini Y, Hochberg Y. Controlling the False Discovery Rate: a practical and powerful approach to multiple testing. J Roy Stats Soc (B) 1995;57:289-300.

36. Shovlin CL, Sulainam NL, Govani FS, Jackson JE, Begbie ME. Elevated Factor VIII in hereditary haemorrhagic telangiectasia (HHT): association with venous thromboembolism. Thrombosis and Haemostasis 2007;98:1031-9.

37. CEMACH. Saving mothers lives 2003-2005 (Full report).

38. Shovlin CL, Jackson JE, Hughes JMB. Pulmonary arteriovenous malformations and other pulmonary vascular disorders. In: Mason RJ, Broaddus CVC, Murray JF, Nadel JA, editors. Murray and Nadel's Textbook of Respiratory Medicine, 4th edition. Philadelphia: Elsevier Saunders; 2005. p. 1480-1501.

39. Easey AJ, Wallace GMF, Hughes JM, Jackson JE, Taylor WJ, Shovlin CL. Should asymptomatic patients with hereditary haemorrhagic telangiectasia (HHT) be screened for cerebral vascular malformations? Data from 22,061 years of HHT patient life. J Neurol Neurosurg Psych 2003;74:743-8.

40. Sage DJ. Epidurals, spinals and bleeding disorders in pregnancy: a review. Anaesth Intensive Care 1990;18:319-326. 


\section{Legends for Figures}

\section{Figure 1: Typical non-florid HHT telangiectasia on tongue and finger}

Telangiectasia are also commonly observed on the lips and oral mucosa.

\section{Figure 2: Maternal complications during pregnancy}

A) Case 1: Haemoptysis: Appearances of modest PAVM (arrowed). B) Case 2: Haemothorax: Bi) lobectomy image of surface PAVM with $2 \mathrm{~cm}$ diameter sac (arrowed) which ruptured. Bii) Histopathology of ruptured aneurysm, with point of rupture (narrow arrow) at lower border. Note region of endothelial intimal fibrous proliferation (thick arrow) probably secondary to endothelial damage in these malformations. C) Case 16: Haemorrhagic stroke: Cerebral CT scan of a 26 year old para 3 at 7 months gestation. Ci) CT scan demonstrates massive intraventricular haemorrhage with significant ventricular dilatation Cii) The causative partly calcified carotico-ophthalmic aneurysm in the anterior part of the circle of Willis (arrowed). There was also cisternal blood supporting a herald subarachnoid bleed. D) Case 17: Myocardial infarction. Post mortem cardiac histology: The dead myocytes (pink, anuclear cells) surrounded by neutrophils indicate a recent (within $48 \mathrm{hs}$ ) acute transmural myocardial infarction. There was accompanying pulmonary oedema and bilateral pleural effusions of $500 \mathrm{mls}$. Coronary arteries displayed a hint of coronary atheroma but no narrowing or embolism. There was no evidence of vasculitis. Sections of the right ventricle were normal. We speculate that an undiagnosed pulmonary AVMs contributed to her death, causing a paradoxical embolic coronary artery thrombosis which had dissipated at the time of death 24 hours later: HHT patients have a venous prothrombotic tendency via elevated Factor VIII levels ${ }^{37}$, and pulmonary AVMs provide a conduit for paradoxical emboli. 
Figure 1

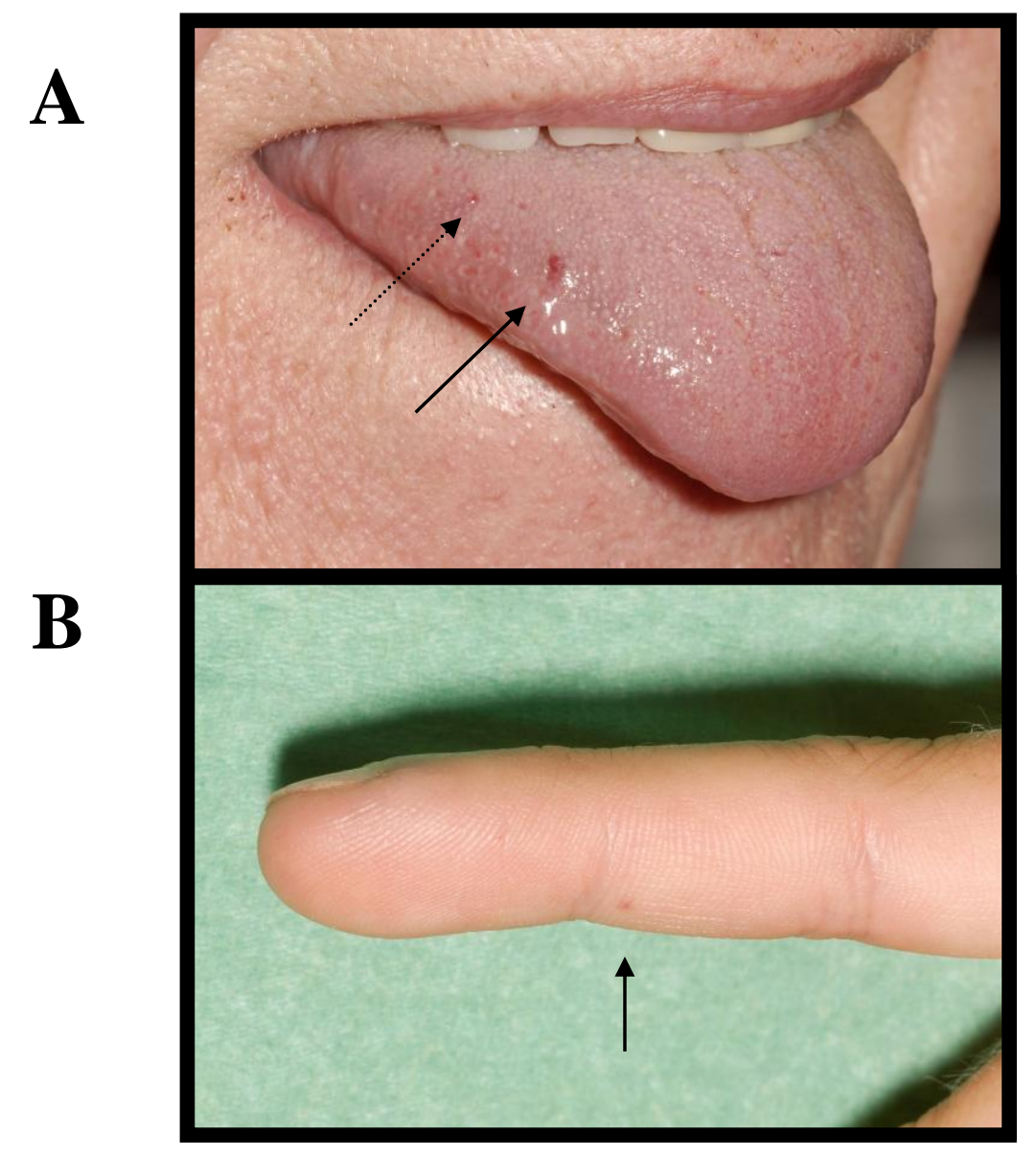


Figure 2

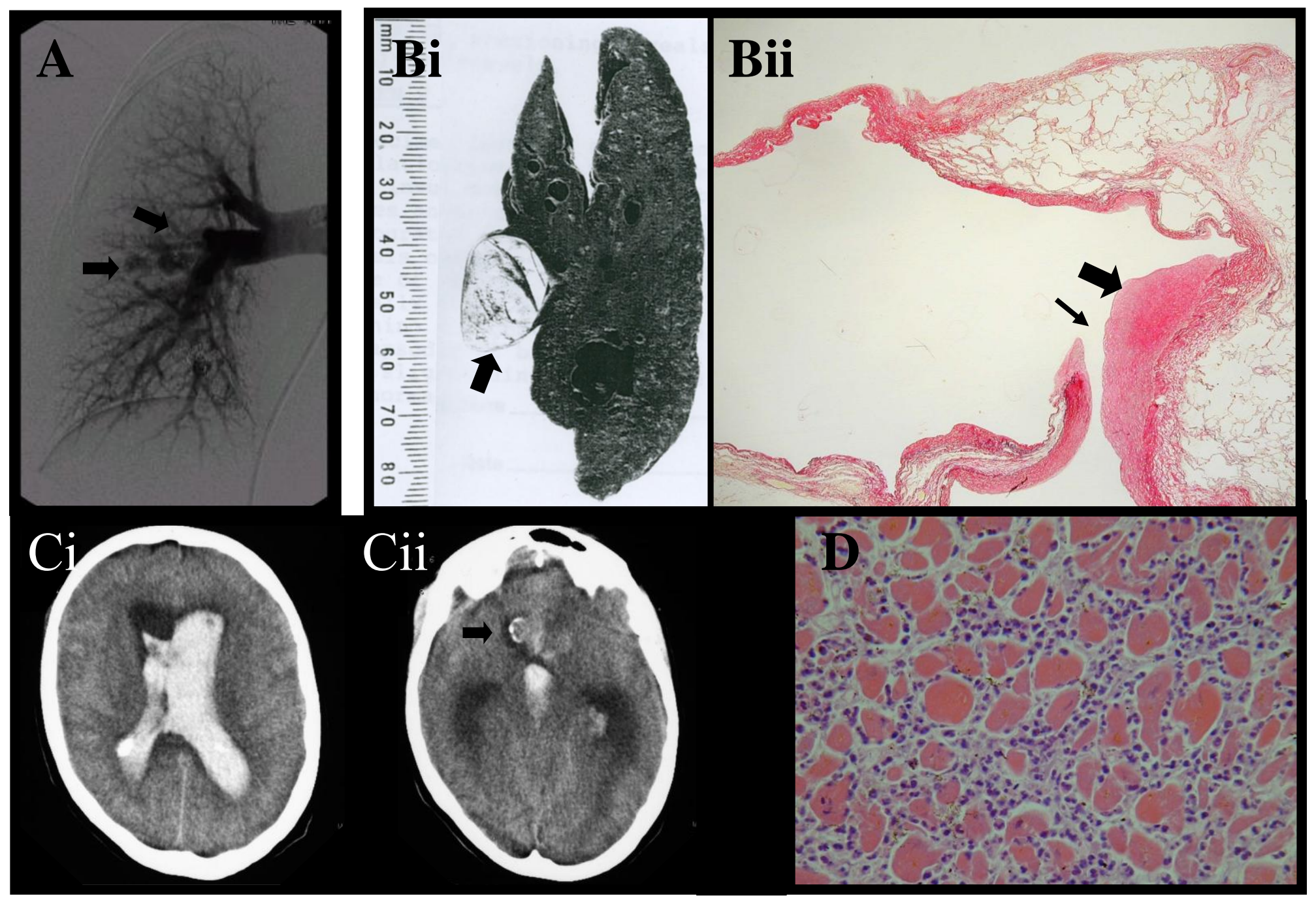

